RGSA - Revista de Gestão Social e Ambiental

Set. - Dez. 2010, v.4, n.3, p. 3-17 ${ }^{1}$

www.gestaosocioambiental.net

\title{
A UTILIZAÇÃO DO BALANÇO SOCIAL COMO FERRAMENTA DE VERIFICAÇÃO DA APLICAÇÃO DA LEI No 8.213/91: UM ESTUDO MULTI-CASO DAS INSTITUIÇÕES FINANCEIRAS BRASILEIRAS COM AÇÕES NEGOCIADAS NA BOVESPA
}

Sandro Vieira Soares

Acadêmico do Curso de Ciências Contábeis - sandrovieirasoares@hotmail.com

\section{Kamille Simas Ebsen}

Mestre em Contabilidade pela Universidade Federal de Santa Catarina - UFSC kamilles_ufsc@hotmail.com

\section{Aldeci de Borba Vargas}

Bacharel em Ciências Contábeis pela Universidade Federal de Santa Catarina - UFSC aldeci_vargas@yahoo.com.br

\section{Maria Denize Henrique Casagrande}

Doutora em Engenharia de Produção e Docente do Departamento de Ciências Contábeis da Universidade Federal de Santa Catarina - denize@cse.ufsc.br.

\section{Resumo}

Esta pesquisa trata da aplicação da legislação referente aos direitos dos portadores de necessidades especiais e da contribuição da contabilidade para a aplicação desta legislação usando o modelo IBASE de Balanço Social como ferramenta. Para tanto, foram analisados os Balanços Sociais das companhias abertas do setor bancário com ações listadas na BOVESPA. A pesquisa compreende o demonstrativo referente aos exercícios sociais de 2005, 2006, 2007 e 2008. As empresas que compuseram a amostra foram aquelas cujos Balanços Sociais dos referidos períodos foram disponibilizados em seus sítios eletrônicos. A pesquisa mostrou que há uma modificação que pode ser realizada na metodologia de elaboração do modelo IBASE, de forma a uniformizar a evidenciação da informação referente à participação dos portadores de necessidades especiais nos quadros de funcionários. A pesquisa também apontou que apenas uma das empresas analisadas cumpriu as exigências legais e isto ocorreu somente em um dos períodos analisados. Por fim, a pesquisa mostrou que apesar de a maioria das empresas estarem em situação irregular quanto à legislação pertinente, elas têm apresentado avanços em incluir portadores de necessidades especiais na composição de seus quadros de colaboradores.

Palavras-chave: Portadores de necessidades especiais. Balanço Social. Instituições bancárias. Lei 9.213/91.

\footnotetext{
Abstract

${ }^{1}$ Recebido em 31.05.2010. Aprovado em 08.07.2010. Disponibilizado em 26.11.2010. Avaliado pelo sistema double blind review
} 
This research addresses the implementation of the legislation concerning the rights of people with special needs and the contribution of accounting for such an implementation through the use of IBASE's Social Balance report. Thus, an analysis of the Social Balance sheet of the banking sector whose companies have shares listed at BOVESPA was undertaken. The survey comprised the aforementioned statement related to the fiscal years of 2005, 2006, 2007 and 2008. The companies that composed the sample were those whose Social Balance sheets of those periods were available on their websites. The research showed that a change can be made in the methodology of the IBASE model in order to standardize the disclosure of information concerning the participation of individuals with special needs in the working staff of the companies. The research also showed that only one of the companies analyzed fulfilled the legal requirements and only in one of the periods under scrutiny. Finally, the research revealed that although the majority of the companies are in an irregular situation regarding this special kind of legislation, they have made some progress in including people with special needs in their staff.

Keywords: People with special needs. Social Balance sheet. Banks. Law n. 9213/91.

\section{INTRODUÇÃO}

Alguns dos efeitos da prática de responsabilidade social corporativa dentro das instituições são divulgados pelas empresas com a finalidade de accountability ou marketing social. As boas iniciativas das empresas como investimentos em educação, cultura, lazer, preservação do meio ambiente ou recuperação de áreas degradadas são evidenciados pelas companhias em seus relatórios de administração, relatórios de sustentabilidade e balanço social.

Godoy (2007) afirma que no Brasil existem três modelos de balanços sociais mais utilizados pelas empresas: o Global Reporting Iniciative - GRI, o modelo do Instituto Ethos e o modelo IBASE. O modelo IBASE é dividido em categorias que tratam de bases de cálculo, investimentos sociais internos, externos, ambientais, indicadores do corpo funcional, exercício da cidadania empresarial e outras informações.

A categoria de indicadores do corpo funcional descreve o quadro de funcionários sobre aspectos como o número de admissões e demissões no período, percentual de mulheres e negros em cargos de chefia, número de estagiários e número de portadores de necessidades especiais. A Lei $n^{0} 8.213 / 91$, em seu artigo 93, define as faixas percentuais que cada companhia deverá empregar de portadores de necessidades especiais dentro de seus quadros de funcionários conforme o número total funcionários.

Diante desses fatos, o objetivo desta pesquisa é analisar por meio de seus balanços sociais, se um determinado grupo de sociedades por ações de capital aberto que atuam no setor bancário cumpre com o estabelecido no artigo 93 da Lei n ${ }^{\circ}$ 8.213/91.

\section{METODOLOGIA}

Esta pesquisa se trata de uma pesquisa documental, pois se baseia em fontes primárias de dados, que são os Balanços Sociais (Gil, 1991). A pesquisa documental difere da pesquisa bibliográfica em função da origem dos dados analisados, tendo em vista que a pesquisa documental utiliza dados primários e a bibliográfica utiliza dados secundários sendo que estes já passaram por alguma forma de análise.

A abordagem desta pesquisa se caracteriza como quanti-qualitativa; quantitativa pois os dados coletados foram mensurados percentualmente para verificar o cumprimento legal e qualitativa pois o enquadramento dos resultados nas faixas estipuladas em lei se dá em função da interpretação da lei e dos resultados obtidos. O método quantitativo é caracterizado pelo 
uso da quantificação no tratamento dos dados (Richardson, 1999) e o método qualitativo trata da análise dos aspectos que adjetivam os dados analisados.

Esta pesquisa se caracteriza como descritiva, pois descreve a realidade quanto à inserção dos portadores de necessidades especiais no mercado de trabalho e o cumprimento do artigo 93 da Lei no 8.213/91 pelas instituições financeiras de capital aberto no Brasil entre os anos de 2005 e 2008. Sobre a pesquisa descritiva, Triviños (1992) afirma que esta tem o objetivo de delinear a realidade observada.

A pesquisa desenvolvida teve como foco as empresas do setor bancário com ações negociadas na BM\&FBovespa em julho de 2008. As empresas que compunham a população foram:

\begin{tabular}{|l|l|}
\hline Alfa Holdings S.A. & Banco Mercantil do Brasil S.A. \\
\hline Banestes S.A. - Banco do Estado do Espírito Santo & Banco Nordeste do Brasil S.A. \\
\hline Banco Abc Brasil S.A. & Banco Nossa Caixa S.A. \\
\hline Banco Alfa de Investimento S.A. & Banco Panamericano S.A. \\
\hline Banco Amazonia S.A. & Banco Patagonia S.A. \\
\hline Banco Bradesco S.A. & Banco Pine S.A. \\
\hline Banco do Brasil S.A. & Banco Santander S.A. \\
\hline Banco Cruzeiro do Sul S.A. & Banco Sofisa S.A. \\
\hline Banco Daycoval S.A. & Brb Banco de Brasilia S.A. \\
\hline Banco Estado de Santa Catarina S.A. & Consorcio Alfa de Administracao S.A. \\
\hline Banco Estado de Sergipe S.A. - Banese & International Finance Corporation \\
\hline Banco Estado do Para S.A. & Itausa Investimentos Itau S.A. \\
\hline Banco Estado do Piaui S.A. & Parana Banco S.A. \\
\hline Banco Estado do Rio Grande do Sul S.A. & Renner Participacoes S.A. \\
\hline Banco Industrial e Comercial S.A. & Unibanco Holdings S.A. \\
\hline Banco Indusval S.A. & Unibanco União de Bancos Brasileiros S.A. \\
\hline Banco Itau Holding Financeira S.A. & Votorantim Finanças S.A \\
\hline Banco Mercantil de Investimentos S.A. & \\
\hline
\end{tabular}

Quadro 1 - Empresas do setor bancário listadas na BM\&FBovespa em 2008

Fonte - Dados da pesquisa

Foram analisados os relatórios os relatórios dos exercícios de 2005, 2006, 2007 e 2008, por apresentarem resultados recentes. Das 35 empresas foram consultados os sítios eletrônicos de 30 enquanto que os sítios de outras 5 não foram encontrados: Alfa Holdings S.A., Banco Mercantil do Brasil S.A., Consórcio Alfa de Administração S.A., International Finance Corporation e Renner Participações S.A. O sítio das empresas Unibanco Holdings S.A. e Unibanco União de Bancos Brasileiros S.A. é comum as duas empresas, e o Balanço Social divulgado por elas está sob a denominação de Grupo Unibanco e contém as informações de ambas. As informações da empresa Banco Itaú Holding Financeira S.A. estão incorporadas pela empresa Itausa Investimentos Itau S.A. que é controladora. Deste modo foi considerado, nesta pesquisa, apenas do conglomerado já que este contém as informações daquela. Outros dois fatos ocorridos entre as empresas que compuseram a amostra foi a incorporação do Besc pelo Banco do Brasil e a fusão entre o Itaú e Unibanco em 2008.

Das 30 empresas restantes foi apurado que as empresas Banco Amazônia S.A. e o Banco Estado de Sergipe S.A. - Banese elaboraram e publicaram BS somente até os anos de 2004 e 2005, respectivamente.

Das demais empresas foram encontrados BS apenas das seguintes instituições: Banco Bradesco S.A., Banco do Brasil S.A., Banco do Estado de Santa Catarina S.A., Banco Industrial e Comercial S.A., Banco de Brasília S.A., Banco Estado de Sergipe S.A. - Banese, Banco Nordeste do Brasil S.A. e as empresas Unibanco União de Bancos Brasileiros S.A. e Unibanco Holdings S.A. que são divulgadas em conjunto, assim como a Itausa Investimentos 
Itau S.A. e Banco Itaú Holding Financeira S.A., que emitem BS individualmente, mas foi considerado apenas da Itausa pelos motivos já expostos. Nesta pesquisa, essas empresas serão tratadas pelas denominações de: Bradesco, B. Brasil, Besc, Bicbanco, B. Brasília, Banese, B. Nordeste, Itausa e Unibanco, respectivamente.

\section{FUNDAMENTAÇÃO TEÓRICA}

A responsabilidade social, que consiste em práticas de ações éticas voltadas para o bem-estar da sociedade, tem permanecido em foco na mídia há vários anos e indícios de sua adoção e prática são observados em vários ambientes e em vários graus. No ambiente econômico ela tem dado origem às chamadas empresas socialmente responsáveis. De Luca (2005) define a responsabilidade social empresarial como uma forma de gestão ética e transparente com todos os seguimentos da sociedade.

A dimensão das ações e reações baseadas na prática da responsabilidade social apontada pela autora compreende os ambientes internos e externos à empresa porque ações internas podem afetar o ambiente interno e externo assim como ações externas.

A responsabilidade social é definida como a consciência ética e o agir corretamente na gestão empresarial levando em consideração as conseqüências que as ações empresariais podem causar aos stakeholders e a sociedade como um todo (Reis e Medeiros, 2007).

Também aqui os autores destacam a relação entre a empresa e o meio na qual ela está inserida sob a forma dos stakeholders. Os enunciados dos conceitos de responsabilidade social por diversos autores podem ser diferentes, mas a idéia gira em torno de que é necessário que os indivíduos assumam sua responsabilidade pelo meio no qual está inserido e que esses indivíduos ajam de modo a contribuir para a melhoria e sustentabilidade das condições ambientais, sociais e econômicas desse meio.

Pode-se dizer que um dos frutos resultantes da aplicação da responsabilidade social pela contabilidade em suas atividades é o Balanço Social - BS. O BS é uma demonstração contábil de publicação não obrigatória por lei no Brasil que evidencia os aspectos sociais das entidades aos usuários da informação contábil.

De acordo com Tinoco (2008) o Balanço Social é uma ferramenta de gestão e de informação que objetiva evidenciar informações econômicas e sociais referentes ao desempenho das entidades para os usuários da informação, do modo mais transparente possível.

Rebouças afirma que o Balanço Social também é visto como uma demonstração técnica gerencial que abrange informações sociais que permitem a agentes econômicos visualizarem as ações sociais para empregados, entidades de classe, governo e de cidadania (como citado em Pinto e Ribeiro, 2005, p. 40).

As informações apresentadas pelos BSs são evidenciadas por pontos de vista diferentes e podem ser de natureza quantitativa ou qualitativa. Em um BS pode-se encontrar informações referentes ao desempenho econômico da empresa, aos seus programas sociais, ao meio ambiente e a outros aspectos relevantes em forma de montantes investidos ou mesmo descrição dos aspectos sociais da empresa.

Podem-se conceituar os aspectos sociais como os esforços e investimentos por parte da empresa no bem estar dos seus colaboradores, na melhoria da qualidade de vida da comunidade na qual está inserida e na preservação do meio ambiente bem como a geração de renda pela atividade desenvolvida e sua distribuição.

A sociedade merece ser informada dos esforços da empresa pelo bem estar das pessoas, e a divulgação desses esforços são benéficos às empresas quer do ponto de vista de sua imagem perante consumidores, quer do ponto de vista do disclosure de sua gestão (Tinoco e Kraemer, 2004). 
A afirmação acima é corroborada por Iudícibus (2006) quando este diz que "o objetivo básico da contabilidade (...) pode ser resumido no fornecimento de informações econômicas para vários usuários, de forma que propiciem decisões racionais” (p. 25).

No entanto o BS, por ser de publicação voluntária, não segue uma padronização. Existem atualmente três modelos mais usuais que as empresas brasileiras têm adotado para a divulgação de suas informações sócio-econômico-ambientais: o modelo IBASE, o modelo do Instituto Ethos e o Global Reporting Initiative - GRI (Godoy, 2007).

O Quadro 2 elenca alguns dos indicadores de cada modelo de Balanço Social:

\begin{tabular}{|c|l|}
\hline Modelo & \\
\hline \multirow{4}{*}{ IBASE } & Base de Cálculo \\
\cline { 2 - 3 } & Indicadores Sociais Internos \\
\cline { 2 - 3 } & Indicadores Sociais Externos \\
\cline { 2 - 3 } & Indicadores Ambientais \\
\cline { 2 - 3 } & Indicadores do Corpo Funcional \\
\cline { 2 - 3 } & Informações Relevantes \\
\hline \multirow{5}{*}{ GRI } & Indicadores de Desempenho Econômico \\
\cline { 2 - 3 } & Indicadores de Desempenho do Meio Ambiente \\
\cline { 2 - 3 } & Indicadores de Desempenho Referentes a Práticas Trabalhistas e Trabalho Decente \\
\cline { 2 - 3 } & Indicadores de Desempenho Referentes a Direitos Humanos \\
\cline { 2 - 3 } & Indicadores de Desempenho Referente à Sociedade \\
\cline { 2 - 3 } Ethos & Indicadores de Desempenho Referentes à Responsabilidade pelo Produto \\
\hline \multirow{5}{*}{ Instituto } & Valores, Transparência e Governança \\
\cline { 2 - 3 } & Público Interno \\
\cline { 2 - 3 } & Meio Ambiente \\
\cline { 2 - 3 } & Fornecedores \\
\cline { 2 - 3 } & Consumidores e Clientes \\
\cline { 2 - 3 } & Comunidade \\
\cline { 2 - 3 } & Governo e Sociedade \\
\hline
\end{tabular}

Quadro 2 - Indicadores e seções dos modelos IBASE, GRI e Instituto Ethos

Fonte - Adaptado de Godoy (2007).

O modelo desenvolvido pelo Instituto Brasileiro de Análises Sociais e Econômicas IBASE tornou-se conhecido como modelo IBASE e pode-se verificar no sítio eletrônico deste mesmo instituto algumas das empresas que adotaram este modelo.

Segundo Souza (1997 apud Serra Negra et. al., 2002), a idéia do Balanço Social é demonstrar quantitativamente e qualitativamente o papel desempenhado entidades na esfera social e isso aspectos internos e externos como: educação, saúde, cuidados com o meioambiente e com a qualidade de vida e de trabalho dos funcionários. Um aspecto observado é que este modelo, analogamente as outras demonstrações contábeis, deve ser publicado com os resultados do ano anterior de modo que atenda ao critério de comparabilidade dos investimentos (como citado em Serra Negra et. al., 2002).

Esse modelo, que tem foco nos indicadores financeiros dos investimentos das empresas, apresenta as informações de forma sintética o que facilita a sua elaboração e pode estimular a opção de construí-lo e publicá-lo. O modelo IBASE está dividido em critérios que são: 'Base de Cálculo', 'Indicadores Sociais Internos', 'Indicadores Sociais Externos', 'Indicadores Ambientais', 'Indicadores do Corpo Funcional', 'Informações Relevantes quanto ao Exercício da Cidadania Empresarial’ e ‘Outras Informações’.

\begin{tabular}{|l|l|}
\hline \multicolumn{1}{|c|}{ Seção } & \multicolumn{1}{c|}{ Componentes } \\
\hline Base de Cálculo & Receita líquida, Resultado operacional e Folha de pagamento bruta. \\
\hline $\begin{array}{l}\text { Indicadores Sociais } \\
\text { Internos }\end{array}$ & $\begin{array}{l}\text { Alimentação, Saúde, Previdência privada, Educação, Cultura, Auxílios-creche, Saúde e } \\
\text { Segurança do trabalho }\end{array}$ \\
\hline $\begin{array}{l}\text { Indicadores Sociais } \\
\text { Externos }\end{array}$ & $\begin{array}{l}\text { Educação, Cultura, Saúde, Saneamento, Esporte, Combate à fome na comunidade, } \\
\text { Subsídios e patrocínios a programas de inclusão social }\end{array}$ \\
\hline Indicadores & Investimentos de preservação e recuperação do meio ambiente ligados ou não às \\
\hline
\end{tabular}




\begin{tabular}{|l|l|}
\hline Ambientais & atividades da empresa. \\
\hline $\begin{array}{l}\text { Indicadores do } \\
\text { Corpo Funcional }\end{array}$ & $\begin{array}{l}\mathrm{N}^{\circ} \text { total de empregados, de admissões, de empregados terceirizados, de estagiários, de } \\
\text { empregados com mais de 45 anos, de mulheres e de negros bem como os percentuais de } \\
\text { cargos de chefia ocupados por mulheres e negros. }\end{array}$ \\
\hline $\begin{array}{l}\text { Exercício } \\
\text { Cidadania } \\
\text { Empresarial }\end{array}$ & da \\
\hline Outras Informações & Todas as outras informações relevantes \\
\hline \multicolumn{2}{|c|}{$\begin{array}{r}\text { Quadro 3 - Divisões do modelo IBASE } \\
\text { Fonte - Adaptado de IBASE (2008). }\end{array}$} \\
\hline
\end{tabular}

Os Indicadores Sociais Internos devem evidenciar o número total de funcionários ao final de cada exercício e o total de admissões durante o exercício. Essas informações em conjunto permitem saber a taxa de rotatividade dos funcionários. O número de empregados terceirizados também é uma informação importante para definir como a empresa está interagindo com o mercado. O número de estagiários permite saber se a empresa oferece oportunidade de inserção do mercado de trabalho para graduandos. O número de empregados acima de 45 anos mostra se a empresa não está excluindo esse tipo de mão-de-obra. O número de mulheres e negros e o percentual dos mesmos em relação ao total dos empregados informam se a empresa está fazendo a inclusão social por raça e por gênero embora se deva ter muito cuidado ao analisar os dados referentes à raça pois há o fato de que esse dado só se refere aos funcionários que assim se classificam e também há que se verificar a composição da população local para se saber se há realmente inclusão social ou não.

Há ainda o número de pessoas com deficiência ou necessidades especiais. Em relação a isso cabe ressaltar que não há uma regra específica de como contar o número de pessoas que se enquadram nesse quesito e isso pode gerar problemas de interpretação porque há diferenças conceituais entre as definições de deficiência.

A Organização Mundial de Saúde - OMS (1989) define deficiência como perda ou anormalidade da estrutura ou função psicológica, fisiológica ou anatômica. A incapacidade está ligada a qualquer redução ou falta de capacidades, em decorrência de deficiência, para exercer atividades específicas, dentro dos limites considerados normais para os seres humanos. A desvantagem é definida pelo impedimento sofrido por um indivíduo de exercer determinada atividade em decorrência de deficiência ou incapacidade considerando gênero, idade e fatores sócio-culturais (como citado em Machado, 2001).

Verifica-se no exposto acima que a OMS adotou uma diferenciação quanto ao critério de classificação de portador de necessidade especial procurando melhor tratar o assunto. No entanto há também o conceito dado pela legislação brasileira como o Decreto nº 914/93 em seu $3^{\circ}$ artigo que é:

"Art. $3^{\circ}$ Considera-se pessoa portadora de deficiência aquela que apresenta, em caráter permanente, perdas ou anormalidades de sua estrutura ou função psicológica, fisiológica ou anatômica, que gerem incapacidade para o desempenho de atividade, dentro do padrão considerado normal para o ser humano."

Essas diferenças conceituais, segundo Marshaw et. al. (1996), embora pareçam pequenas, são responsáveis pelas diferenças das seguintes estimativas feitas em relação à população de portadores de necessidades especiais segundo alerta (como citado em Pastore, 2000, p. 37):

"Quando se consideram todas as pessoas que possuem algum tipo de doença crônica ou restrição que impõe limitação ao pleno funcionamento do seu corpo ou da sua mente, $50 \%$ da população (ou mais) são portadores de deficiência em qualquer país do mundo. Quando se levam em conta só as pessoas que tem limitações para o trabalho, o percentual se reduz a 10\%. Quando se focalizam as que estão em idade de trabalhar a proporção cai para $6 \%$ ou $7 \%$. E quando se consideram apenas os casos de limitações mais severas, a proporção desce para $2 \%$.” 
Ou seja, dependendo da metodologia para a classificação dos portadores de necessidades especiais os percentuais podem variar significativamente. E isso é de extrema importância devido ao fato de que a classificação errônea pode enquadrar uma empresa como que não sendo obediente a lei.

O artigo 93 da lei 8.213/91 determina os percentuais de pessoas portadoras de necessidades especiais que devem compor o seu quadro se funcionários de acordo com o porte da empresa e a escolha errada do critério de classificação dos funcionários portadores de necessidades especiais podem mostrar um descumprimento a essa lei. O texto do artigo 93 diz que:

\footnotetext{
“A empresa com 100 (cem) ou mais empregados está obrigada a preencher de $2 \%$ (dois por cento) a 5\% (cinco por cento) dos seus cargos com beneficiários reabilitados ou pessoas portadoras de deficiência, habilitadas, na seguinte proporção: I - até 200 empregados............................................................2\%; contrato por prazo determinado de mais de 90 (noventa) dias, e a imotivada, no contrato por prazo indeterminado, só poderá ocorrer após a contratação de substituto de condição semelhante.

$\S 2^{\circ} \mathrm{O}$ Ministério do Trabalho e da Previdência Social deverá gerar estatísticas sobre o total de empregados e as vagas preenchidas por reabilitados e deficientes habilitados, fornecendo-as, quando solicitadas, aos sindicatos ou entidades representativas dos empregados."
}

Os percentuais descritos acima foram transcritos do artigo 93 da Lei $\mathrm{n}^{\circ}$ 8.213/91, mas a mesma redação usada acima foi utilizada também no artigo 36 do Decreto $n^{0} 3.298$ de 20 de Dezembro de 1999 que dispõe sobre a Política Nacional para a Integração da Pessoa Portadora de Deficiência, consolida as normas de proteção, e dá outras providências.

A definição de quem se enquadra como beneficiários reabilitados ou pessoas portadoras de deficiência citadas nos artigo acima é dada pela Portaria 4.677/98, do Ministério da Previdência e Assistência Social, nos primeiro e segundo parágrafos:

" $\S 1^{\circ}$ Consideram-se beneficiários reabilitados todos os segurados e dependentes vinculados ao Regime Geral de Previdência Social - RGPS, submetidos a processo de reabilitação profissional desenvolvido ou homologado pelo Instituto Nacional do Seguro Social - INSS.

$\S 2^{\circ}$ Consideram-se pessoas portadoras de deficiência, habilitadas, aquelas não vinculadas ao RGPS, que se tenham submetido a processo de habilitação profissional desenvolvido pelo INSS ou por entidades reconhecidas legalmente para este fim.”

Segundo Hepp (2001) dois terços dos países da Europa possuem cotas legais e compulsórias - a maioria baseada em cota-contribuição que permite ao empregador optar entre contratar o portador de necessidade especial ou contribuir compulsoriamente para um fundo público destinado a habilitação e reabilitação de profissionais dos mesmos. Entre os países que adotam o sistema de cotas destacam-se a Áustria, a Alemanha, a Bélgica, a França, a Holanda, a Espanha, a Irlanda, o Japão, a China e Honduras. Nestes as cotas variam entre $1,5 \%$ e $7 \%$.

Esse autor afirma ainda que países como Dinamarca, Suécia, Finlândia, Estados Unidos, Canadá, Nova Zelândia e Austrália rejeitam o sistema de cotas por acreditar que tal sistema constitui uma forma de discriminação quanto à capacidade dos portadores de necessidades especiais de competir no mercado. (Hepp, 2001).

A Organização das Nações Unidas declarou o ano 1981 como o "Ano Internacional das Pessoas Deficientes” como o objetivo de conscientizar todos os países quanto à questão 
das pessoas portadoras de deficiência. Areosa (2004) afirma um marco americano nesta questão foi à promulgação do "The Americans with Disabilities Act of 1990" que em seu Título I proibiu os empregadores de discriminar portadores de deficiência em qualquer esfera trabalhista incluindo contratação e treinamento.

A Constituição da República Portuguesa também aborda o tema em seu artigo 71 transcrito abaixo:

\begin{abstract}
“Artigo $71 .^{\circ}$ - Cidadãos portadores de deficiência
1. Os cidadãos portadores de deficiência física ou mental gozam plenamente dos direitos e estão sujeitos aos deveres consignados na Constituição, com ressalva do exercício ou do cumprimento daqueles para os quais se encontrem incapacitados.

2. O Estado obriga-se a realizar uma política nacional de prevenção e de tratamento, reabilitação e integração dos cidadãos portadores de deficiência e de apoio às suas famílias, a desenvolver uma pedagogia que sensibilize a sociedade quanto aos deveres de respeito e solidariedade para com eles e a assumir o encargo da efectiva realização dos seus direitos, sem prejuízo dos direitos e deveres dos pais ou tutores. 3. O Estado apoia as organizações de cidadãos portadores de deficiência.”
\end{abstract}

A Lei Italiana $n^{\circ} 68$ de 23 de março de 1999 também aborda o número mínimo de vagas que os empregadores devem reservar aos portadores de deficiência como está transcrito abaixo em item 1 do artigo $3^{\circ}$ :

“Art. 3. (Assunzioni obbligatorie. Quote di riserva).

1. I datori di lavoro pubblici e privati sono tenuti ad avere alle loro dipendenze lavoratori appartenenti alle categorie di cui all'articolo 1 nella seguente misura:

a) sette per cento dei lavoratori occupati, se occupano più di 50 dipendenti;

b) due lavoratori, se occupano da 36 a 50 dipendenti;

c) un lavoratore, se occupano da 15 a 35 dipendenti.”

Como se pode ver, na Itália são reservadas 1 vaga em empresas de 15 a 35 empregados, 2 vagas em empresas de 36 a 50 empregados e $7 \%$ das vagas em empresas que possuem mais de 50 empregados.

A contabilidade, no exercício de sua função social, na forma da elaboração e publicação para a sociedade de balanços com os dados que a escrita contábil fornece deve mostrar de forma clara e precisa o modo como as empresas estão desenvolvendo seus programas de inclusão social e seu devido cumprimento da legislação trabalhista que ampara os portadores de necessidades especiais em vigor no país.

Neste sentido, esta pesquisa possui como objetivo geral verificar o cumprimento do artigo 93 da Lei $\mathrm{n}^{\circ}$ 8.213/91, através dos balanços sociais, em empresas do ramo financeiro, classificadas como atividade bancária, com ações negociadas na Bolsa de Valores, Mercadorias e Futuros do Estado de São Paulo - BM\&FBovespa.

Para isto, verificou se a estrutura do modelo de Balanço Social utilizado por essas empresas, no caso das que elaboram Balanço Social, dá suporte para essa verificação. O modelo de Balanço Social escolhido foi o modelo desenvolvido pelo Instituto Brasileiro de Análises Sociais e Econômicas - IBASE.

\title{
4 RESULTADOS DA PESQUISA
}

A amostra encontrada referente ao exercício de 2005 foi composta pelas empresas Bradesco, B. Brasil, Besc, Bicbanco, B. Brasília, Banese, B. Nordeste, Itausa e Unibanco sendo que as empresas Besc, Banese e Unibanco apresentaram peculiaridades. Os bancos Besc e Unibanco não relacionaram o número de portadores de necessidades especiais em seus BS. O banco Banese, em seu relatório anual divulgou apenas o percentual que os portadores de necessidades especiais representavam dentro de seu quadro de colaboradores sem, contudo, apresentar os valores numéricos. 
Através dos dados da Tabela 1, observa-se que ao final do exercício social de 2005 nenhuma empresa atingiu percentual mínimo de 4\% de empregados portadores de necessidades especiais, conforme determinação da alínea III, do artigo 93, da Lei 8.213/91. Com o índice de 3,29\% a empresa Bicbanco apresentou o maior índice da amostra daquele período.

Tabela 1 - Relação entre o quadro funcional total e portadores de necessidades especiais em 2005. 2005

\begin{tabular}{l|c|c|c}
\hline Empresa & $\mathrm{N}^{\circ}$ total de funcionários & $\mathrm{N}^{\circ}$ de portadores & Índice (\%) \\
\hline Bradesco & 73.881 & 769 & 1,04 \\
\hline B. Brasil & 83.751 & 1.437 & 1,71 \\
\hline Besc & 3.048 & SI $^{1}$ & - \\
\hline Bicbanco & 638 & 21 & 3,29 \\
\hline B. Brasília & 2.156 & 10 & 0,46 \\
\hline Banese & $\mathrm{SI}^{1}$ & $\mathrm{SI}^{1}$ & 0,4 \\
\hline B. Nordeste & 4.407 & 23 & 0,52 \\
\hline Itausa & 62.128 & 1.627 & 2,62 \\
\hline Unibanco & 29.504 & $\mathrm{SI}^{1}$ & - \\
\hline \multicolumn{4}{r}{$\mathrm{SI}^{1}:$ Sem Informação. } \\
\end{tabular}

No exercício social de 2006, a amostra foi composta por Bradesco, B. Brasil, Besc, Bicbanco, B. Brasília, B. Nordeste, Itausa e Unibanco, sendo que o BS do Banco Banese não compôs a Tabela 2 por não ter sido publicado em seu sítio eletrônico.

Tabela 2 - Relação entre o quadro funcional total e portadores de necessidades especiais em 2006.

\begin{tabular}{l|c|c|c}
\hline \multicolumn{5}{|c}{2006} \\
\hline Empresa & $\mathrm{N}^{\circ}$ total de funcionários & $\mathrm{N}^{\circ}$ de portadores & Índice (\%) \\
\hline Bradesco & 79.306 & 860 & 1,08 \\
\hline B. Brasil & 82.672 & 1.473 & 1,78 \\
\hline Besc & 3.142 & 38 & 1,21 \\
\hline Bicbanco & 665 & 23 & 3,46 \\
\hline B. Brasília & 2.314 & 14 & 0,60 \\
\hline B. Nordeste & 5.161 & 26 & 0,50 \\
\hline Itausa & 71.774 & 1.755 & 2,44 \\
\hline Unibanco & 32.956 & 118 & 0,36 \\
\hline \multicolumn{4}{|c|}{ Fonte - Dados da pesquisa }
\end{tabular}

Verificou-se neste período as empresas, cujos relatórios foram localizados, que elaboraram BS de forma completa, divulgando o total de funcionários e destes, o total de portadores de necessidades especiais. Isto permitiu inferir que, novamente, nenhuma empresa atendeu as disposições legais. Nesta nova análise, o Bicbanco tornou a apresentar o maior índice deste setor enquanto o Unibanco apresentou o menor, apesar do número de empregados portadores de necessidades especiais deste ser aproximadamente quatro vezes superior que o daquele.

Comparando os exercícios de 2005 e 2006, a Tabela 3 evidencia a variação percentual no número total de funcionários e o número de portadores de necessidades especiais. A amostra utilizada para tal comparação foi composta pelas empresas Bradesco, B. Brasil, Bicbanco, B. Brasília, B. Nordeste e Itaúsa, pois estas apresentaram dados nos dois exercícios.

Tabela 3 - Variação percentual do número total de funcionários e número total de portadores de necessidades especiais entre os anos de 2005 e 2006.

\begin{tabular}{l|c|c}
\hline \multicolumn{3}{c}{ VARIAÇÃO (\%) } \\
\hline Empresa & $\mathrm{N}^{\circ}$ total & $\mathrm{N}^{0}$ de portadores \\
\hline Bradesco & 7,34 & 11,83 \\
\hline
\end{tabular}




\begin{tabular}{l|c|c}
\hline B. Brasil & $-1,29$ & 2,50 \\
\hline Bicbanco & 4,23 & 9,52 \\
\hline B. Brasília & 7,33 & 40,00 \\
\hline B. Nordeste & 17,11 & 13,04 \\
\hline Itausa & 15,52 & 7,87 \\
\hline TOTAL & 6,58 & 6,79 \\
\hline \multicolumn{2}{|c}{ Fonte - Dados da pesquisa }
\end{tabular}

A análise dos dados evidencia que, com exceção do Banco do Brasil, todas as empresas aumentaram o seu quadro de funcionários com destaque para o Banco do Nordeste, com $17,11 \%$.

Da amostra de empresas de 2006, que possuíam informações referentes a 2005, comparando com as informações das Tabelas 1, 2 e 3 observou-se também que apenas a empresa Itaúsa teve redução no percentual de funcionários portadores de necessidades especiais em relação ao quadro total, mesmo aumentando em valores absolutos tanto o número total de funcionários quanto de portadores de necessidades especiais. Isto porque enquanto o número de funcionários portadores de necessidades especiais aumentou em aproximadamente 7,87\% o número total de funcionários aumentou quase o dobro, 15, 52\%.

Verifica-se também que todas as empresas que compuseram a amostra com dados em 2005 e 2006 aumentaram o número de portadores de necessidades especiais em seu quadro de funcionários, mesmo tendo redução do quadro total, como o Banco do Brasil. Contudo, observa-se que o aumento ou redução do percentual de funcionários portadores de necessidades especiais não é proporcional ao aumento ou redução no quadro total de funcionários, o que sugere que não há, por parte das empresas analisadas, política de vinculação do percentual deste com aquele.

Para o exercício de 2007 a amostra foi composta pelas mesmas empresas da amostra de 2006, evidenciada na Tabela 4.

Tabela 4 - Relação entre o quadro funcional total e portadores de necessidades especiais em 2007.

\begin{tabular}{l|c|c|c}
\hline \multicolumn{4}{|c}{2007} \\
\hline Empresa & $\mathrm{N}^{\circ}$ total de funcionários & $\mathrm{N}^{0}$ de portadores & Índice (\%) \\
\hline Bradesco & 82.773 & 1.075 & 1,30 \\
\hline B. Brasil & 81.900 & 765 & 0,93 \\
\hline Besc & 3.126 & 38 & 1,21 \\
\hline Bicbanco & 823 & 27 & 3,28 \\
\hline B. Brasília & 2.275 & 121 & 5,32 \\
\hline B. Nordeste & 5.726 & 19 & 0,33 \\
\hline Itausa & 78.003 & 2.540 & 3,25 \\
\hline Unibanco & 34.215 & 366 & 1,07 \\
\hline
\end{tabular}

Fonte - Dados da pesquisa

Ao analisar a Tabela 4, verificou-se que o Banco de Brasília passou a apresentar o maior índice de portadores de necessidades especiais entre as empresas selecionadas, sendo o único a atingir a meta legal para empresas com mais de mil funcionários, com 5,32\%.

Análise conjunta com a Tabela 2, evidencia um aumento no índice de portadores de necessidades especiais em quatro das oito empresas analisadas. Houve redução em três empresas e apenas uma manteve o mesmo índice do exercício anterior.

O Banco de Brasília aumentou em comparação a 2006, seu índice de portadores de necessidades especiais em 4,72 pontos percentuais. Isto porque enquanto seu quadro total de funcionários reduziu em $1,68 \%$ o de portadores de necessidades especiais aumentou em $764,28 \%$, conforme demonstrado na Tabela 5, que evidencia a variação percentual no quadro total de funcionários e de funcionários portadores de necessidades especiais. 
Tabela 5 - Variação percentual do número total de funcionários e número total de portadores de necessidades especiais entre os anos de 2006 e 2007.

\begin{tabular}{l|c|c}
\hline \multicolumn{3}{|c}{ VARIAÇÃO (\%) } \\
\hline Empresa & $\mathrm{N}^{\circ}$ total & $\mathrm{N}^{\circ}$ de portadores \\
\hline Bradesco & 4,37 & 25,00 \\
\hline B. Brasil & $-0,97$ & $-48,06$ \\
\hline Besc & $-0,51$ & 0,00 \\
\hline Bicbanco & 23,76 & 17,39 \\
\hline B. Nordeste & 10,95 & $-26,92$ \\
\hline B. Brasília & $-1,68$ & 764,28 \\
\hline Itausa & 8,68 & 44,73 \\
\hline Unibanco & 3,82 & 210,17 \\
\hline TOTAL & 3,89 & 14,85
\end{tabular}

Através da Tabela 5 verifica-se ainda que, apesar do número total de funcionários do Banco do Brasil ter reduzido, em relação ao ano anterior: menos de 1\%, o número de portadores de necessidades especiais reduziu em 48,06\%. Foi a única, das três empresas com redução no quadro total de funcionários, que reduziu, também, o quadro de funcionários portadores de necessidades especiais.

Verificou-se também que dentre as seis empresas que tiveram variação positiva no quadro total de funcionários apenas uma apresentou variação negativa no quadro de funcionários portadores de necessidades especiais, o Banco Nordeste que apresentou variação positiva de 10,95\% no quadro total de funcionários enquanto seu quadro de funcionários portadores de necessidades especiais reduziu em 26,92\%.

Verificou-se também que, assim como ocorreu em 2006, a variação no quadro de funcionários portadores de necessidades especiais não acompanhou, de forma proporcional, a variação no quadro total de funcionários, o que sugere que não há, também no exercício de 2007, por parte das empresas da amostra, política de proporcionalidade de vagas para portadores de necessidades especiais em relação ao quadro total de funcionários.

Em 2008, a amostra foi composta pelos bancos Bradesco, Bicbanco, Banco de Brasília, Banco do Nordeste, e pelo Itaú Unibanco Holding S.A. Não foram encontradas as informações sobre número de portadores de deficiência do Banco do Brasil e do Besc, este último incorporado ao Banco do Brasil neste exercício.

Tabela 6 - Relação entre o quadro funcional total e portadores de necessidades especiais em 2008.

\begin{tabular}{l|c|c|c}
\hline \multicolumn{4}{|c}{2008} \\
\hline Empresa & $\mathrm{N}^{\circ}$ total de funcionários & $\mathrm{N}^{\circ}$ de portadores & Índice (\%) \\
\hline Bradesco & 86.622 & 1.285 & 1,48 \\
\hline Bicbanco & 814 & 28 & 3,44 \\
\hline B. Brasília & 2.283 & 9 & 0,39 \\
\hline B. Nordeste & 5.978 & 24 & 0,40 \\
\hline Itaú Unibanco & 108.027 & 2.736 & 2,53 \\
\hline
\end{tabular}

Fonte - Dados da pesquisa

A análise do Itaú e Unibanco foi feita em conjunto dada a fusão realizada pelas duas instituições no ano de 2008. Destaca-se novamente o percentual atingido pelo Bicbanco que foi o mais próximo de atingir os limites legais.

Contudo, pode-se verificar na Tabela 6, referente ao ano de 2008, que nenhuma empresa atingiu o percentual mínimo estabelecido em lei. O Banco de Brasília que em 2007, e pela primeira vez entre os exercícios analisados, foi o único a atingir o percentual legal não atingiu tal percentual em 2008, reduzindo em 4,93 pontos percentuais. Isto porque o número 
de funcionários portadores de necessidades especiais passou de 121 para apenas 09, uma queda de 92,56\% (Tabela 8).

Considerando as empresas que apresentaram dados em 2007 e a análise conjunta Unibanco/Itaú verifica-se que das cinco empresas analisadas no exercício de 2008 três empresas aumentaram o índice de portadores de necessidades especiais: Bradesco, Bicbanco e Banco do Nordeste.

Comparando os exercícios de 2007 e 2008, a Tabela 7 evidencia a variação no quadro total de funcionários e no quadro de funcionários portadores de necessidades especiais.

Tabela 7 - Variação percentual do número total de funcionários e número total de portadores de necessidades especiais entre os anos de 2007 e 2008.

\begin{tabular}{l|c|c}
\hline \multicolumn{3}{|c}{ VARIAÇÃO (\%) } \\
\hline Empresa & $\mathrm{N}^{\circ}$ total de empregados & $\mathrm{N}^{\mathrm{o}}$ de portadores \\
\hline Bradesco & 4,65 & 19,53 \\
\hline Bicbanco & $-1,09$ & 3,70 \\
\hline B. Brasília & 0,35 & $-92,56$ \\
\hline B. Nordeste & 4,40 & 26,32 \\
\hline Itaú Unibanco & $-3,73$ & $-5,85$ \\
\hline TOTAL & $-0,045$ & $-1,591$ \\
\hline \multicolumn{2}{c}{ Fonte - Dados da pesquisa }
\end{tabular}

Pode-se verificar que o conjunto das empresas que compuseram a amostra reduziu seus quadros de funcionários em aproximadamente $0,04 \%$ enquanto que o total de portadores de necessidades especiais que trabalhavam nestas empresas reduziu em um pouco mais de $1,5 \%$.

Verifica-se, também, que apenas duas empresas tiveram variação positiva no quadro total de funcionários: Bradesco, Banco de Brasília e Banco do Nordeste sendo que apensar da variação positiva, o Banco de Brasília apresentou variação negativa no número de funcionários portadores de necessidades especiais. Dentre as três empresas que apresentaram variação negativa no quadro total de funcionários apenas uma apresentou variação positiva no quadro de portadores de necessidades especiais.

Assim, conforme análise comparativa dos demais exercícios sociais observa-se que em 2008 também não houve vinculação na política de proporcionalidade entre o quadro total de funcionários e o quadro de portadores de necessidades especiais, pois o aumento/redução deste não implicou em aumentos/redução daquele.

A Tabela 8 demonstra os totais de funcionários ao final de cada exercício de todas as empresas somadas, além do somatório do número de portadores de necessidades especiais e dos percentuais que os últimos representavam nos quadros de funcionários.

Tabela 8 - Relação entre o total de funcionários e total de portadores de necessidades especiais.

\begin{tabular}{c|c|c|c}
\hline Ano & $\mathrm{N}^{\circ}$ total & $\mathrm{N}^{\circ}$ de portadores & \% do total \\
\hline 2005 & 226.961 & 3.887 & 1,71 \\
\hline 2006 & 241.892 & 4.151 & 1,71 \\
\hline 2007 & 251.500 & 4.547 & 1,81 \\
\hline 2008 & 203.724 & 4.082 & 2,00 \\
\hline \multicolumn{3}{|c}{ Fonte - Dados da pesquisa }
\end{tabular}

O número total dos funcionários das empresas consideradas foi de 226.961, 241.892, 251.500 e 203.724 nos anos de 2005, 2006, 2007 e 2008 respectivamente. O exercício de 2008 apresentou um somatório de funcionários menor que 2007 em função das demissões mas também em função da desconsideração do Banco do Brasil e Besc na análise. Apesar disso, 2008 foi o exercício que apresentou maior percentual de portadores de necessidades especiais. Tal percentual manteve-se estável em 2005 e 2006, com 1,71\% e começou a crescer a partir de 2007 atingindo em 2008 o índice de $2 \%$. 
A análise da Tabela 8 sugere que há um esforço por parte das empresas em aumentar a participação dos portadores de necessidades especiais em seu quadro de funcionários, porém, como observado também nas Tabelas 3, 5 e 7 o aumento no quadro total de funcionários não está vinculado de forma proporcional ao aumento no quadro de portadores de necessidades especiais.

A pesquisa também apontou que para manter a consistência das informações apresentadas é necessário que o modelo IBASE forneça a definição precisa do funcionário que pode ser considerado portador de necessidade especial. Além disto é necessário também que as empresas utilizem um modelo padrão, a fim de permitir de modo mais conciso a análise de tal demonstrativo.

\section{CONCLUSÕES E SUGESTÕES}

Os objetivos do trabalho que eram verificar se as empresas do setor bancário com ações listadas na BM\&FBovespa estavam em conformidade com o artigo 93 da Lei 8.213/91 e se os Balanços Sociais emitidos pelas mesmas forneciam informação para essa análise foram atingidos.

A pesquisa mostrou que no ano de 2005 e 2006 nenhuma das empresas que compunham a amostra atingiu os percentuais destacados em lei e mostrou também, que no ano de 2007 uma das empresas pesquisadas atingiu o percentual necessário mas não manteve esse percentual em 2008. As análises feitas sobre os dados coletados apontaram que há um esforço por parte das empresas para atingir os percentuais determinados em lei.

A análise da metodologia de elaboração dos Balanços Sociais e da legislação mostrou um ponto que se modificado pode fazer do modelo IBASE uma ferramenta de fiscalização da lei. A metodologia do modelo estudado não define a classificação de quem pode ser considerado portador de necessidade especial e a sugestão que esta pesquisa faz é de que sejam classificados como portadores de necessidades especiais para fins de elaboração do Balanço Social aquelas listadas nos dois primeiros parágrafos da Portaria 4.677/98, do Ministério da Previdência e Assistência Social.

Sugere-se para trabalhos futuros que o pesquisador entre em contato com as empresas para questionar a respeito da auditoria deste tipo de informação social e também para descobrir como essas empresas estão conseguindo aumentar a participação dos portadores de necessidades especiais em seus quadros de funcionários e quais as dificuldades que essas empresas estão encontrando para atingir esse objetivo.

Sugere-se também questionar as empresas analisadas sobre qual das definições existentes sobre deficiência foi adotada para a divulgação das informações.

\section{REFERÊNCIAS}

Areosa, A. L. (2004). O portador de necessidades especiais e o mercado de trabalho: a contribuição da ergonomia no processo de inclusão do PNEs no setor fumageiro. Tese de Doutorado. Programa de Pós-Graduação em Engenharia de Produção, Universidade Federal de Santa Catarina, Florianópolis, SC, Brasil.

Brasil. (1991). Lei $n^{\circ} 8.213$ de 24 de julho de 1991. Dispõe sobre os Planos de Benefícios da Previdência Social e dá outras providências. Brasília, DF. Recuperado em 28 de maio, 2010, de http://www.planalto.gov.br/ccivil_03/Leis/L8213cons.htm

De Luca, M. M. M. (2005). Responsabilidade Social - um diferencial competitivo para as empresas. Revista Brasileira de Contabilidade, 34 (152), p. 25-34. 
Gil, A. C. (1991). Como elaborar projetos de pesquisa. (3a Ed). São Paulo: Atlas.

Godoy, M. (2007). As divergências e convergências nas informações disponibilizadas no Balanço Social entre três modelos utilizados no Brasil. Monografia de Graduação, Departamento de Ciências Contábeis, Universidade Federal de Santa Catarina, Florianópolis, SC, Brasil.

Hepp, M. R. G. (2001). O comportamento do gerente de agência bancária frente ao portador de deficiência: um estudo de caso. Dissertação de Mestrado. Programa de Pós-Graduação em Engenharia de Produção, Universidade Federal de Santa Catarina, Florianópolis, SC, Brasil.

Instituto Brasileiro de Análises Sociais e Econômicas - IBASE. (2008). Publique seu Balanço Social. Recuperado em 23 de Julho, 2008, de: http://www.balancosocial.org.br/cgi/cgilua.exe/sys/start.htm.

Itália. (1999). Legge 12 marzo 1999, n. 68. Norme per il diritto al lavoro dei disabili. Roma. Recuperado em 31 de maio, 2010, de http://www.parlamento.it/parlam/leggi/990681.htm.

Iudícibus, S. (2006). Teoria da Contabilidade. (8a Ed.) São Paulo: Atlas.

Machado, C. V. C. (2001). Inclusão do Deficiente no Campo de Trabalho. Dissertação de Mestrado. Programa de Pós-Graduação em Engenharia de Produção, Universidade Federal de Santa Catarina, Florianópolis, SC, Brasil.

Pastore, J. (2000). Oportunidades de trabalho para portadores de deficiência. São Paulo: LTr.

Pinto, A. L., Ribeiro M. S. (2005). O Balanço Social como instrumento de evidenciação de responsabilidade social: um estudo no estado de Santa Catarina. Revista Brasileira de Contabilidade, 34 (154), p. 37-50.

Portaria 4.677 de 29 de julho de 1998 (1998). Dispõe sobre o número mínimo de funcionários portadores de necessidades especiais que as empresas devem contratar segundo o porte da empresa. Brasília, DF. Recuperado em 28 de maio, 2010, de http://www.nppd.ms.gov.br/legislacao.asp?lei_id=22.

Portugal. (1974). Constituição da República Portuguesa. Lisboa. Recuperado em 31 de maio, 2010, de http://www.parlamento.pt/Legislacao/Paginas/ConstituicaoRepublicaPortuguesa.aspx.

Reis, C. N., Medeiros, L. E. (2007). Responsabilidade Social das Empresas e Balanço Social. São Paulo: Atlas.

Richardson, R. J. (2008). Pesquisa Social: métodos e técnicas. (3a Ed). São Paulo: Atlas.

Serra Negra, C. A., Teixeira, F. S., Carmo, R. F. (2002). O Balanço Social na gestão das instituições de ensino superior. Revista Brasileira de Contabilidade, 31 (138), p. 68-87.

Tinoco, J. E. P. (2008). Balanço Social - Uma abordagem da transparência e da Responsabilidade Pública das Organizações. São Paulo: Atlas. 
Tinoco, J. E. P., Kraemer, M. E. P. (2004). Contabilidade e Gestão Ambiental. São Paulo: Atlas.

Triviños, A. N. S. (1987). Introdução à pesquisa em ciências sociais: a pesquisa qualitativa em educação. São Paulo: Atlas. 